\title{
Rabaska
}

Revue d'ethnologie de l'Amérique française

El Yamani, Myriame et Jacques Pasquet (sous la direction de), Nadia Baribault, Dominique Breau, Myriame El Yamani, Alfred Leger, Nelson Michaud, Yvettte Pitre, Robert Richard. Parlures d'Acadie. Montréal, Planète rebelle, " Paroles ", 2007, 92 p. + CD. ISBN 978-2-922528-76-3

\section{Maurice Lamothe}

Volume 6, 2008

URI : https://id.erudit.org/iderudit/000036ar

DOI : https://doi.org/10.7202/000036ar

Aller au sommaire du numéro

Éditeur(s)

Société québécoise d'ethnologie

ISSN

1703-7433 (imprimé)

1916-7350 (numérique)

Découvrir la revue

Citer ce compte rendu

Lamothe, M. (2008). Compte rendu de [El Yamani, Myriame et Jacques Pasquet (sous la direction de), Nadia Baribault, Dominique Breau, Myriame El Yamani, Alfred Leger, Nelson Michaud, Yvettte Pitre, Robert Richard. Parlures d'Acadie. Montréal, Planète rebelle, « Paroles », 2007, 92 p. + CD. ISBN 978-2-922528-76-3]. Rabaska, 6, 175-177. https://doi.org/10.7202/000036ar d'utilisation que vous pouvez consulter en ligne. 
El Yamani, Myriame et Jacques Pasquet (sous la direction de), Nadia Baribault, Dominique Breau, Myriame El Yamani, Alfred Leger, Nelson Michaud, Yvettte Pitre, Robert Richard. Parlures d'Acadie. Montréal, Planète rebelle, « Paroles », 2007, 92 p. + CD. ISBN 978-2922528-76-3.

Les chemins menant à la sélection des œuvres littéraires dignes de publication sont multiples. Ceux qui s'offrent à la littérature orale répondent à des critères qui lui sont propres et à d'autres qu'elle partage avec la littérature écrite. S'il arrive qu'à l'instar des grandes œuvres, des contes et des légendes revus et corrigés, aient subi l'épreuve de la durée, le procès spécifique à l'oralité des œuvres demeure, pour sa part, indissociable de l'efficacité de la performance, et cela, d'autant plus que l'œuvre orale sera originale. En revanche, lorsqu'il n'est pas le créateur, comme dans le cas des contes traditionnels, c'est dans l'originalité de sa dérive interprétative que le conteur peut encore prétendre au statut d'auteur, un statut conféré aux sept conteurs dont les noms figurent sur la page couverture de Parlures d'Acadie.

Parlures d'Acadie est autant le fruit de l'épreuve du temps que de celui du public en face duquel les diverses histoires ont été racontées. C'est bien ce qu'il faut comprendre de la préface de Myriame El Yamani et de Jacques Pasquet qui associent la pertinence de la publication de Parlures d'Acadie à un processus de reconnaissance qui le liait à un public, soit les deux Nuits internationales du conte en Acadie (NICA) en 2002 et 2003 ; une notoriété extérieure ensuite, en France en 2004, où «le succès fut au rendez-vous ». C'est en 2005, nous disent les préfaciers que des « artistes confirmés et de la relève $[\ldots]$ ont décidé ensemble » d'offrir leurs histoires à un projet de publication d'un recueil de contes accompagné d'un disque compact.

Les différences entre les trames audio et écrite sont relativement importantes et mériteraient sans doute, à elles seules, une longue analyse ; ce dont nous nous abstiendrons cependant. Constatons pour l'heure que le transfert des codes, de l'oral à un écrit plus littéraire, n'affecte en rien les trames narratives tout en pavant la voie à une lecture plus fluide.

Le seul conte traditionnel du recueil est « Le Bâtiment blanc », présenté par Robert Richard, où le héros trouve son faire-valoir chez un géant dont la méchanceté innommable sera endiguée grâce à la ruse et à la bonté du plus petit.

Parlures d'Acadie offre au lecteur trois contes de création. Le premier met à nouveau en présence un héros dont le destin le conduira à vaincre bien plus fort que lui ; "L'Arbre de Théodule » de Nadia Baribault est en fait un pommier exceptionnel, symbole de la générosité du héros, à l'origine duquel une multitude de vergers serviront à nourrir des villages; ce qui aura pour première conséquence, non seulement d'affranchir les villageois de la faim, mais aussi, de l'oppression des seigneurs. Deuxième création, « Une histoire 
de temps » de Nelson Michaud, explore une veine bien connue du conte traditionnel où un pacte avec le diable est conclu autour d'un échange entre les richesses matérielles et l'âme du héros. La conclusion qui permettra au héros de conserver autant ses richesses que son âme s'impose ici comme une métaphore du triomphe des valeurs temporelles déculpabilisées sur la morale traditionnelle qui, en Acadie, dévalorise argent et pouvoir. Myriame El Yamani, pour sa part, dans un troisième conte de création, tranche par son appel aux marins et une ouverture d'esprit vis-à-vis cette étrangère aux habitudes suspectes que le capitaine a épousée. Médire à son propos, nous dit le conte, peut provoquer la colère de la mer !

Une chronique de village cette fois, présentée par Dominique Breau et intitulée "Chroniques de mon village », raconte avec humour une série de petites histoires où l'autorité morale de l'Église est remise en question. Le conteur explique en effet de quelle manière son village «a réussi à passer deux curés en une semaine ».

Myriame El Yamani revient cette fois avec une courte adaptation littéraire d'un conte traditionnel intitulé «L'Île des sentiments ». Ici encore la mer, source de chaos, sera mise à contribution. Pour échapper à l'engloutissement, tous les sentiments de l'île décident de partir à l'exception de l'Amour qui, lui, demeurera fidèle à sa terre natale et sera sauvé grâce au Temps, autre personnage du conte.

Un mythe revu et corrigé par Alfred Leger, «La Véritable Histoire de Noé et de son arche », raconte l'incroyable histoire de l'arche de Noé qui se serait échouée dans la baie des Chaleurs. La valeur du récit tient essentiellement ici à la crédibilité du conteur qui a recours à des personnages historiques dont il cite les déclarations que l'on devra tenir pour vérifiées ou vérifiables. Le conteur termine son histoire par un conseil à «ceux qui allument inconsidérément des feux sur la plage avec du bois échoué. Avezvous imaginé $[\ldots]$ que vous étiez peut-être en train de faire disparaître en fumée les restes de l'épave de l'arche?»

Enfin, « La Messe en latin », ce récit de vie transformé en conte présenté par Yvette Pitre, pose un regard humoristique sur le rituel des célébrations religieuses en latin des années cinquante. Le récit s'ouvre sur l'arrivée de deux étrangères de l'Île-du-Prince-Édouard qui ne « vont point à la messe. Pas même à la confesse pour se faire pardonner leurs péchés...» Véritable critique de la ritualisation religieuse d'une époque, «La Messe en latin » donne un aperçu des distorsions interprétatives dont ont pu avoir été l'objet des fidèles à qui l'on s'adressait « dans une langue morte » et étrangère. À titre d'exemple, cette transformation de l'Asperges me en latin qui, à l'oreille distraite, aurait pu se métamorphoser en un : «mes asperges sont toutes levées ». 
En somme, force est de conclure ici que Parlures d'Acadie apparaît comme une source fort diversifiée et efficace de diffusion de la littérature orale dont les paroles méritaient certes une conservation sur supports imprimé et audio. Enfin, les constants rappels à un contexte acadien dans les différents récits contribuent, sans l'ombre d'un doute, à redonner vie à une parole que l'on aimerait universelle.

Maurice Lamothe

Université Sainte-Anne, Pointe-de-l’Église

Enckell, Pierre. Dictionnaire des jurons. Préface de Jacques Réda. Ouvrage publié avec le concours du Centre national du livre. [Paris], Presses universitaires de France, [2004], 801 p. ISBN 2-13-053933-5.

Journaliste et écrivain, Pierre Enckell est aussi un lexicographe prolifique qui a déjà livré quelques dictionnaires thématiques sur des aspects singuliers de la langue. Parmi sa production récente, on compte un Dictionnaire des façons de parler du XVI siècle (CNRs, 2000), un Dictionnaire des noms des chiens (Mots et Cie, 2000), un Dictionnaire des onomatopées (PuF, 2003), en collaboration avec Pierre Rézeau, et un relevé des perles du Grand Larousse intitulé Que faire des crétins? (Seuil, 2006). Entre ces deux dernières publications, il faisait paraître en 2004 un volumineux Dictionnaire des jurons - entendons des Français de l'Hexagone. De toute évidence, ce compilateur d'expérience, qui hante depuis des années le corpus des écrits français du $\mathrm{XVI}^{\mathrm{e}}$ siècle à nos jours, aura pu, au fil des nombreuses lectures qu'ont entraînées ses lexiques antérieurs, accumuler en parallèle des notes considérables sur la matière de ce livre. L'auteur lève d'emblée tout doute sur ce point : sa cueillette de «quelques milliers de jurons français » provient en effet de « la lecture assidue d'une grande quantité de textes fort variés, savants ou populaires, en prose ou en vers », soit environ « deux mille titres sélectionnés » (p. 10). De facture classique, l'ouvrage s'organise autour du dictionnaire lui-même (p. [37]-723), encastré entre une introduction essentielle (p. [11]-35) et des annexes : une anthologie (p. [725]-741), une bibliographie (p. [743]-786) et un index (p. [787]-800).

Le prologue est sobre, mais il expose utilement la nécessité du projet, une idée que d'autres avaient annoncée sans la réaliser jamais. Au terme de la recension des tentatives avortées ou prétendues, détaillée dans une longue note, l'auteur trouve cette situation anormale, voire gênante : «De ce fait, aucun dictionnaire compréhensif des jurons n'a été publié en France à ce 